\title{
Fístula entero-vesical en enfermedad de Behçet
}

\author{
C. Sevilla Cecilia, J.M. Rodríguez de Ledesma Vega, A.Cetina, W. Marin - Hargreaves*, \\ H. Villavicencio
}

Unidad de Urgencias. Fundación Puigvert.

*Servicio de Cirugía General. Hospital de la Sta. Creu y San Pau.

Actas Urol Esp 2005; 29 (1): 119

$\mathrm{P}$ aciente mujer de 74 años de edad con antecedentes de enfermedad de Behçet con afectación intestinal. En 2000 fue intervenida por un cuadro de diverticulitis aguda perforada realizándose intervención de Hartmann. Desde entonces ha presentado varias fístulas enterocutáneas y enterovesicales tratadas de manera conservadora $\mathrm{y}$ en algunos casos quirúrgica.

En el último ingreso presentaba fístula enterocutáneo-vesical por lo que fue intervenida dejando asa fistulizada aislada en cúpula vesical y anastomosis termino-terminal intestinal.

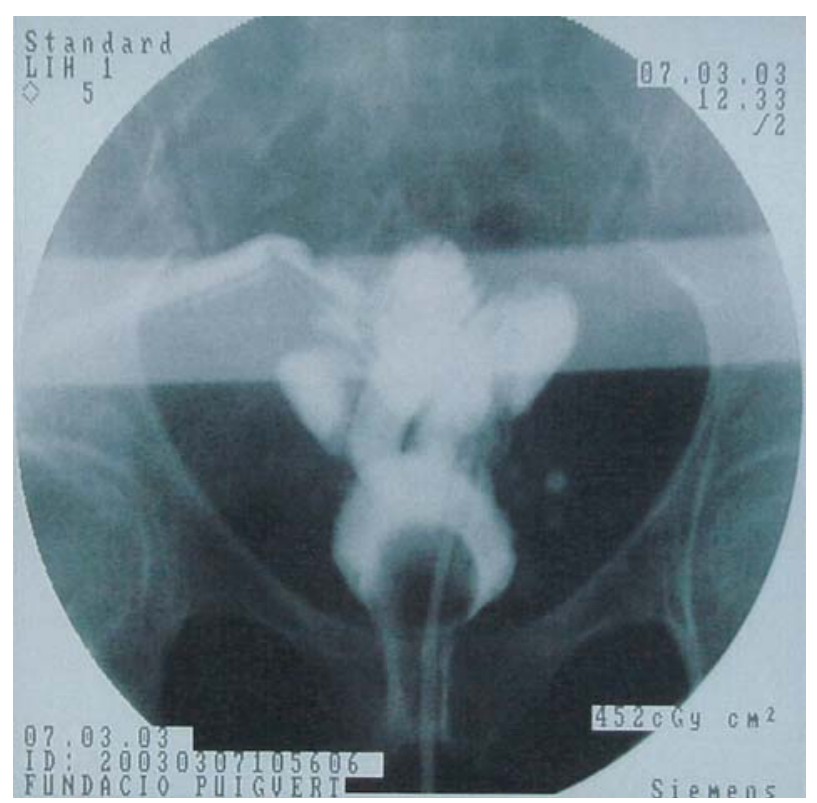

FIGURA I.
En el curso postoperatorio se observa salida de líquido urinoso por drenaje pelviano. Se realiza cistografía (Fig. 1) en la que se demuestra fístula a nivel del asa excluida. Se decide realizar tratamiento conservador con derivación de ambos riñones con sondas de nefrostomía y sonda vesical con retirada progresiva del drenaje pelviano.

A las 2 semanas se realiza pielografía anterógrada y nueva cistografia de control comprobándose el cierre de la fistula. (Fig. 2).

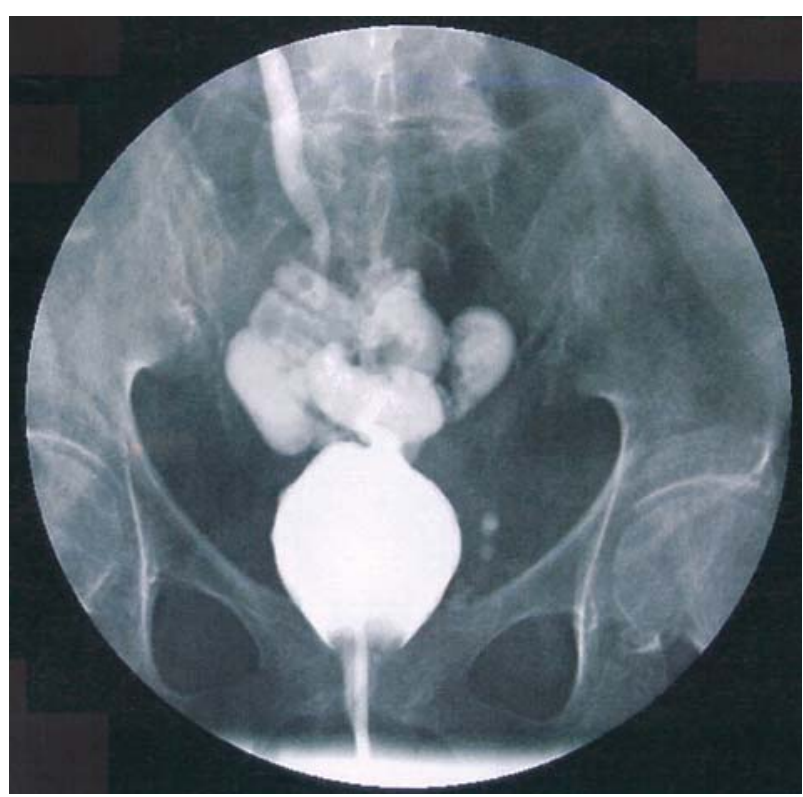

FIGURA 2. 